\title{
Estimating the value of infectious or noninfectious foot disorder prevention strategies within dairy farms, as influenced by foot disorder incidence rates and prevention effectiveness
}

\author{
K. A. Dolecheck, ${ }^{1 *}$ M. W. Overton, ${ }^{2}$ T. B. Mark, ${ }^{3}$ and J. M. Bewley ${ }^{4}$ \\ ${ }^{1}$ Department of Animal and Food Sciences, University of Kentucky, Lexington 40546 \\ 2Elanco Animal Health, 2500 Innovation Way, Greenfield, IN 46140 \\ ${ }^{3}$ Department of Agricultural Economics, University of Kentucky, Lexington 40546 \\ ${ }^{4}$ Alltech Inc., 3031 Catnip Hill Rd., Nicholasville, KY 40356
}

\section{ABSTRACT}

A farm-level stochastic simulation model was adapted to estimate the value of implementing foot disorder prevention on a dairy farm by calculating the return on investment associated with implementation of foot disorder prevention. Two potential strategies for foot disorder prevention were tested: strategy 1 was prevention focused on reducing infectious foot disorders (i.e., digital dermatitis) in the model, and strategy 2 was prevention focused on reducing noninfectious foot disorders (i.e., sole ulcer and white line disease) in the model. For each strategy, we evaluated the effect of foot disorder incidence on the value of prevention by setting the incidence of foot disorders at 3 levels. For strategy 1 , the level of digital dermatitis incidence without prevention in all parities was 20,40 , or $60 \%$, and the incidence level of the noninfectious foot disorders in the model were held constant. For strategy 2, levels of sole ulcer and white line disease incidence without prevention in parity $\geq 3$ cows were 5,15 , or $25 \%$, and the incidence level of the infectious foot disorders included in the model were held constant; the incidence levels of noninfectious foot disorders in younger cows were adjusted to be lower. Overall, 6 scenarios were run, 1 for each prevention strategy $\times$ foot disorder incidence rate combination. To evaluate how the effectiveness of each prevention strategy would influence the investment value, the effectiveness of prevention could vary from a prevention risk ratio $(\mathrm{RR})$ of $0.0(100 \%$ reduction in disorder incidence) to 1.0 ( $0 \%$ reduction in disorder incidence). When implementing strategy 1 , the return on prevention investment per cow-year (mean \pm standard deviation) when prevention effectiveness was low (prevention $\mathrm{RR}=0.91$ to 1.0 ) and the digital

Received May 1, 2018.

Accepted September 20, 2018.

*Corresponding author: karmella.dolecheck@uky.edu dermatitis incidence rate was originally 20,40 , or $60 \%$ was $\$ 0.6 \pm 0.4, \$ 1.2 \pm 0.9$, and $\$ 1.8 \pm 1.3$, respectively. In comparison, the return on prevention investment per cow-year when prevention effectiveness was high (prevention $R R=0.00$ to 0.09 ) and the digital dermatitis incidence rate was originally 20,40 , or $60 \%$ was $\$ 12.2$ $\pm 3.0, \$ 24.4 \pm 6.0$, and $\$ 36.5 \pm 9.0$, respectively. When implementing strategy 2 , the return on prevention investment per cow-year when prevention effectiveness was low and noninfectious foot disorder incidence rates were originally 5,15 , or $25 \%$ in parity $\geq 3$ cows was $\$ 0.6 \pm 0.4, \$ 1.9 \pm 1.1$, and $\$ 3.2 \pm 1.9$, respectively. In comparison, the return on prevention investment per cow-year when prevention effectiveness was high and noninfectious foot disorder incidence rates were originally 5,15 , or $25 \%$ in parity $\geq 3$ cows was $\$ 12.4$ $\pm 1.5, \$ 37.3 \pm 4.6$, and $\$ 62.2 \pm 7.6$, respectively. The return on investment for foot disorder prevention would depend on the cost of the prevention strategy and the other benefits associated with the selected prevention strategy. This model could be used as a decision support tool to help identify the amount that could be paid to implement a selected prevention strategy.

Key words: lameness, hoof health, decision support, animal health economics

\section{INTRODUCTION}

Lameness, a clinical condition often associated with a variety of different foot disorders, is considered one of the most important animal welfare issues in the dairy industry today (von Keyserlingk et al., 2009) and is estimated to be one of the most expensive dairy diseases per case (Liang et al., 2017). In North American herds, reported lameness prevalence ranged from $10 \%$ (Adams et al., 2017) to 55\% (von Keyserlingk et al., 2012) between 2012 and 2016.

Many foot disorder prevention strategies are available to reduce lameness prevalence in dairy herds, including 
footbaths (Speijers et al., 2012) and preventive hoof trimming (Manske et al., 2002). Yet a recent survey of 184 US dairies indicated that producers are not consistently using recommended foot disorder prevention and control strategies (Adams et al., 2017). Thirty-five percent of surveyed farms never used a footbath and $13 \%$ of farms used a footbath only seasonally or occasionally. Additionally, $7 \%$ of herds never performed preventive hoof trimming, $20 \%$ conducted trimming only when cows were visibly lame, and $36 \%$ performed preventive hoof trimming only once per lactation.

Leach et al. (2010a) found that the reasons producers did not focus on foot disorder prevention included a false perception that no lameness problem existed in their herd, a lack of time, or a lack of understanding surrounding the economic consequences of lameness. Further, when producers were asked what could motivate other farms to reduce lameness, the most frequent response was to provide more information on lameness costs (Leach et al., 2010b). Disease costs are difficult to understand because the total cost is composed of 2 components: expenditures and losses (McInerney et al., 1992). Expenditures are the direct costs associated with treatment (i.e., labor and therapeutics) and prevention of disease. Producers often recall these costs because they are obvious. Losses are the indirect costs associated with existing disease; for example, reduced milk yield, reduced reproductive performance, increased risk of culling, increased risk of death, and risk of disease recurrence are all disease losses. Although not as obvious, losses usually make up the majority of the cost per case of foot disorder (Dolecheck and Bewley, 2018).

Morris (1969) defined optimum disease management as increasing disease prevention expenditures only to the point that the additional money spent would be equal to the resulting additional returns (i.e., reduced losses). In this study, our objective was to use an existing farm-level stochastic simulation model to estimate the return on foot disorder prevention investment. If successful, the model could be used as a decision support tool to help calculate the amount a specific producer should be willing to spend on prevention, given the expected returns (i.e., reduced foot disorder losses). As an example, we used the model to estimate the value of infectious or noninfectious foot disorder prevention strategies when foot disorder incidence rates and prevention effectiveness varied.

\section{MATERIALS AND METHODS}

\section{Model Overview}

The herd-level stochastic simulation model used in this study was first described by Bewley et al. (2010) and has since been adapted by Dolecheck et al. (2019). The deterministic portion of the model was created using Excel 2016 (Microsoft Corp., Redmond, WA) and was supplemented with stochastic features using the @ Risk add-in (Palisade Corp., Ithaca, NY). The model calculates the revenues (milk sales, calf value, and slaughter value) and expenses (feed costs, veterinary costs, breeding costs, and disposal losses) associated with the average cow in the herd every day for 6 lactations. Information about the average cow is used to define all cows in the herd, based on the distribution of cows among parities. After defining the whole herd, the model can be used to estimate the herd-level revenues and expenses each year.

Within the model, the cost per case of 3 foot disorders (digital dermatitis, sole ulcer, and white line disease) was calculated based on assumed changes in cow performance in response to each disorder, as described by Dolecheck et al. (2019). The cost per case of foot disorder varied not only by disorder type, but also by parity group (primiparous or multiparous) and incidence timing (0 to 60,61 to 120,121 to 240 , or $>240$ DIM). The total cost per case of each foot disorder included the current lactation expenditures associated with outside (hoof trimmer) labor, therapeutics, and on-farm labor, and losses associated with discarded milk, reduced milk production, extended days open, increased risk of culling, increased risk of death (natural or euthanized), and foot disorder recurrence (within the same animal). Variables assumed to influence the cost of foot disorders were modeled stochastically to account for variation among herds or uncertainty in their values. For stochastically modeled variables, distributions were selected and defined as described in Dolecheck et al. (2019) using previously published literature or industry averages (Table 1). Each time the model was run, a value from each distribution was selected and used in the model to calculate a unique cost per case of foot disorder.

\section{Foot Disorder Prevention Assumptions}

In this study, the existing model was adapted to estimate the economic outcome associated with implementing foot disorder prevention strategies on a dairy farm. As an example, we focused on 2 potential foot disorder prevention methods: strategy 1 was assumed to reduce infectious foot disorders (i.e., digital dermatitis) only and strategy 2 was assumed to reduce noninfectious foot disorders (i.e., sole ulcer and white line disease) only. To calculate the value of implementing strategies that prevented each type of lameness, the herd-level total cost of lameness would need to be calculated both before and after foot disorder preven- 
Table 1. Simulated market price and herd performance inputs used in a stochastic model to estimate the value of prevention strategies for infectious and noninfectious foot disorders

\begin{tabular}{|c|c|c|c|}
\hline Input & $\begin{array}{c}\text { Simulated range } \\
\text { (minimum-maximum) }\end{array}$ & $\begin{array}{l}\text { Simulated value } \\
(\text { mean } \pm \mathrm{SD})\end{array}$ & Source $^{1}$ \\
\hline Conception rate $(\%)$ & $10-85$ & $39.5 \pm 14.5$ & DairyMetrics \\
\hline Cost of digital dermatitis $(\$ / \text { case })^{2}$ & $29-405$ & $63 \pm 21$ & Dolecheck et al. (2019) \\
\hline Cost of white line disease $(\$ / \text { case })^{2}$ & $92-302$ & $151 \pm 26$ & Dolecheck et al. (2019) \\
\hline Estrus detection rate (\%) & $10-100$ & $56.7 \pm 18.0$ & DairyMetrics \\
\hline Lactating cow feed price $(\$ / \mathrm{kg})$ & $0.22-0.39$ & $0.29 \pm 0.05$ & FAPRI (2018) \\
\hline Prevention effect on foot disorders (risk ratio) & $0.00-1.00$ & $0.50 \pm 0.29$ & Authors' expertise \\
\hline Replacement heifer price $(\$)$ & $1,433-1,885$ & $1,629 \pm 143$ & Gould and Bozic (2018) \\
\hline Rolling herd average milk production $(\mathrm{kg})$ & $4,458-17,974$ & $11,458 \pm 2,003$ & DairyMetrics \\
\hline Slaughter value $(\$ / \mathrm{kg})$ & $1.08-1.89$ & $1.45 \pm 0.22$ & FAPRI (2018) \\
\hline
\end{tabular}

${ }^{1}$ DairyMetrics information was collected on October 1, 2017, from Dairy Records Management Systems (Raleigh, NC). Values gathered from DairyMetrics included 1,987 US Holstein herds with at least 200 cows.

${ }^{2}$ Mean cost per case across all combinations of parity group and incidence timing.

tion implementation. To calculate the herd-level total cost of lameness from the cost per case of foot disorder estimates already provided by the model, the following additional information was needed in the model: foot disorder incidence rates for both before and after prevention implementation and the distribution of foot disorders among different classifications (i.e., the distribution of cases among parities and the distribution of disorder occurrence across the lactation).

Foot Disorder Incidence Rates. For the base scenario, when no foot disorder prevention was used, an estimate of the incidence of each foot disorder was needed. No US studies were identified that evaluated incidence levels of specific foot disorders while reporting the prevention strategies used on the evaluated herds. Additionally, incidence rates will vary across farms. Therefore, in this study, we tested 3 possible incidence rates of foot disorders within each strategy to see how variation would influence the value of investment in foot disorder prevention. Each foot disorder incidence rate was run as a separate simulation within the model. For strategy 1, the incidence of digital dermatitis in all parities was assumed to be 20,40 , or $60 \%$, while the incidence of both sole ulcer and white line disease was held constant (15\%). For strategy 2, the incidence of both sole ulcers and white line disease in parity 3 and greater cows was assumed to be 5,15 , or $25 \%$, while the incidence of digital dermatitis was held constant (30\%). In strategy 2, the incidence of both sole ulcers and white line disease was adjusted in younger animals to account for a lower expected incidence. As suggested by Ettema and Østergaard (2006), the odds of a parity 1 or parity 2 cow having either disease was assumed to be 0.56 or 0.78 of the odds of a parity $\geq 3$ cow. To summarize, 6 scenarios were tested: in 3 scenarios, we tested the economic effect of implementing infectious foot disorder prevention, assuming 3 incidence rates for digital dermatitis; and in 3 scenarios, we tested the economic effect of implementing noninfectious foot disorder prevention, assuming 3 incidence rates for sole ulcers and white line disease. The values chosen to represent incidence rates for all disorders were selected to represent variation around the mean prevalence rates reported by DeFrain et al. (2013) but do not necessarily represent the true incidence rates found on farms in the United States. However, a user could change these values to represent true, on-farm values if using the model as a decision support tool.

When foot disorder prevention strategies were implemented, we assumed that foot disorder incidence would be affected. Risk ratios (RR) were used to adjust the base incidence of each foot disorder as prevention strategies were implemented. A RR is calculated as the incidence in the exposed group divided by the incidence in the unexposed group. In this study, exposure indicates exposure to foot disorder prevention strategies. Limited published data exist on how different foot disorder prevention strategies change foot disorder incidence. Therefore, instead of assuming a particular prevention strategy, we allowed the effect of prevention strategies on foot disorder incidence (prevention RR) to vary stochastically. The prevention RR was modeled using a uniform distribution with the minimum and maximum values set to 0.0 and 1.0, respectively, for all simulations. By doing this, we allowed for the evaluation of both highly effective $(\mathrm{RR}=0.0)$ and highly ineffective $(\mathrm{RR}=1.0)$ prevention strategies, as well as many effectiveness rates in between. For the first 3 scenarios, this $\mathrm{RR}$ was applied to the incidence of digital dermatitis (to allow analysis of the value of infectious foot disorder prevention) and for the remaining 3 scenarios, this RR was applied to the incidence of sole ulcers and white 
line disease (to allow analysis of the value of noninfectious foot disorder prevention).

Foot Disorder Case Classification. The model calculated the cost per case of foot disorder by disorder type, parity group, and incidence timing (Dolecheck et al., 2019). Therefore, the distribution of occurring foot disorder cases among these combinations was needed for an accurate estimation of herd-level lameness costs. Parities $1,2,3,4,5$, and 6 were modeled to represent 36.1, 26.0, 17.7, 11.0, 5.8, and $3.4 \%$ of the herd, respectively (Table 2; Dhuyvetter et al., 2007). Disorder incidence timing was modeled to match timing as reported by Booth et al. (2004), assuming white line disease to follow a similar pattern to sole ulcer because both are noninfectious foot disorders. The percentage of digital dermatitis cases occurring at $\leq 60,61$ to 120 , 121 to 240 , and $>240$ DIM was $26.7,30.9,30.2$, and $12.2 \%$, respectively. The percentage of sole ulcer and white line disease cases occurring at $\leq 60,61$ to 120,121 to 240 , and $>240$ DIM was $26.4,31.8,31.4$, and $10.3 \%$, respectively.

\section{Calculation of Foot Disorder Prevention Value}

In both before and after foot disorder prevention implementation simulations, parity-specific foot disorder incidence rates were multiplied by the number of cows in each parity to calculate the number of cases of each foot disorder occurring in $1 \mathrm{yr}$. To find the number of cows in each parity, the percent of cows in each parity (Table 2) was multiplied by the milking herd size. Milking herd size was modeled stochastically using a PertAlt distribution with the 5th percentile, mean, and 95th percentile set to 50, 250, and 1,000 cows to represent a wide range of herd sizes (Table 1 ). These calculations resulted in the total number of cases of each foot disorder in each parity per year in both the before and after foot disorder prevention implementation scenarios. The number of cases within each parity per year were then distributed among incidence timings using model assumptions, and a cost was assigned to each case by calculating the lameness-associated expenditures and losses, as described in Dolecheck et al. (2019).

In each scenario, the herd-level total cost of lameness was calculated as the sum of all expenditures (outside labor, therapeutics, on-farm labor, and prevention) and losses (discarded milk, reduced milk production, increased days open, an increased risk of culling, an increased risk of death, and disorder recurrence) for all 3 foot disorders over a 1-yr period. This value was converted to the total cost of lameness per lactating cowyear by dividing the herd-level total cost of lameness by the lactating herd size. Within this cost of lameness,

Table 2. Deterministic herd performance and financial inputs used in a stochastic model to estimate the value of prevention strategies for infectious and noninfectious foot disorders

\begin{tabular}{|c|c|c|}
\hline Input & Value & Source $^{1}$ \\
\hline Age at first calving (mo) & 24.3 & DairyMetrics \\
\hline Baseline culling rate $(\%)$ & 13.0 & Bewley et al. (2010) \\
\hline Breeding costs ( $\$$ /insemination) & $15.51^{2}$ & VanRaden and Cole (2014) \\
\hline Butterfat yield (\%) & 3.7 & DairyMetrics \\
\hline Calf birth weight $(\mathrm{kg})$ & 41.7 & Kertz et al. (1997) \\
\hline Calf value ( $\$ /$ bull $)$ & 81.31 & Gould and Bozic (2018) \\
\hline Calf value $(\$ /$ heifer $)$ & 63.47 & Gould and Bozic (2018) \\
\hline Close up dry cow feed price $(\$ / \mathrm{kg}$ of $\mathrm{DMI})$ & 0.22 & Model input \\
\hline Close up dry period length (d) & 21 & Model input \\
\hline Days dry & 56.2 & NAHMS (2014) \\
\hline Days in milk designated "do not breed" & 250 & Bewley et al. (2010) \\
\hline Discount rate $(\%)$ & 8.0 & Hyde and Engel (2002) \\
\hline Disposal losses $(\$)$ & $65^{2}$ & Groenendaal et al. (2004) \\
\hline Far-off dry cow feed price $(\$ / \mathrm{kg}$ of $\mathrm{DMI})$ & 0.15 & Model input \\
\hline Gestation length $(\mathrm{d})$ & 280 & Norman et al. (2007) \\
\hline Mature cow live weight (kg) & 723 & NRC (2001) \\
\hline Percent heifer calves & 46.7 & Silva Del Río et al. (2007) \\
\hline Percent of herd in first parity & 36.1 & Dhuyvetter et al. (2007) \\
\hline Percent of herd in second parity & 26.0 & Dhuyvetter et al. (2007) \\
\hline Percent of herd in third parity & 17.7 & Dhuyvetter et al. (2007) \\
\hline Percent of herd in fourth parity & 11.0 & Dhuyvetter et al. (2007) \\
\hline Percent of herd in fifth parity & 5.8 & Dhuyvetter et al. (2007) \\
\hline Percent of herd in sixth (or greater) parity & 3.4 & Dhuyvetter et al. (2007) \\
\hline Protein yield (\%) & 3.1 & DairyMetrics \\
\hline Voluntary waiting period $(\mathrm{d})$ & 59.3 & DairyMetrics \\
\hline
\end{tabular}

${ }^{1}$ DairyMetrics information was collected on October 1, 2017, from Dairy Records Management Systems (Raleigh, NC). Values gathered from DairyMetrics included 1,987 US Holstein herds with at least 200 cows.

${ }^{2}$ Adjusted for inflation to 2017 prices. 
we did not include the cost of prevention because we were not attempting to model specific prevention strategies. Instead, by comparing the herd-level total cost of lameness per cow-year before and after implementation of the foot disorder prevention strategy, the return on foot disorder prevention investment per cow-year could be calculated, which would represent the maximum amount that could be spent on the foot disorder prevention strategy in each scenario to break even. How this value varied with varying foot disorder incidence rates and implemented prevention strategy effectiveness was also considered.

\section{Simulation Methods}

For this study, 12 simulations of the model were run, as described in Table 3. In 6 simulations, the value of infectious foot disorder prevention was estimated (strategy 1) assuming varying digital dermatitis incidence levels $(20,40$, and $60 \%$ for simulations 1 and 2,3 and 4 , and 5 and 6 , respectively, where odd-numbered simulations were without prevention implementation and even-numbered simulations were with prevention implementation). In the remaining 6 simulations, the value of noninfectious foot disorder prevention was estimated (strategy 2) assuming varying sole ulcer and white line disease incidence levels $(5,15$, and $25 \%$ in parity 3 and greater cows for simulations 7 and 8,9 and 10 , and 11 and 12 , respectively, where odd-numbered simulations were without prevention implementation and even-numbered simulations were with prevention implementation). For each simulation, 1,000 iterations were run using Latin hypercube sampling. To confirm that all simulations used the same drawn stochastic variables for each iteration (making them comparable), a static seed was set to 31,517 . Default deterministic variable assumptions used to define the herd and the average cow were collected from Dairy Records Management Systems (Raleigh, NC) using limitations of only Holstein herds with $\geq 200$ cows, published literature, or the authors' expertise (Table 2). The resulting distributions of herd-level stochastic variables can be found in Table 1. Inputs used in the model for this study were meant to represent a US dairy herd. However, model inputs could be adjusted to herd-specific values to calculate the cost of foot disorders for a specific herd.

\section{RESULTS AND DISCUSSION}

The objective of this study was to use an existing stochastic simulation model to estimate the value of foot disorder prevention strategies when foot disorder incidence rates and prevention effectiveness varied. As shown in Table 3 , the mean \pm SD herd-level total cost of lameness per cow-year was calculated for each simulation, broken down into 10 categories based on the simulated prevention effectiveness level (intervals were by 0.1 from 0.0 to $1.0, \mathrm{n} \sim 100$ iterations/mean). Over the 12 simulations, the herd-level total cost of lameness varied depending on the assumed foot disorder incidence rates, whether foot disorder prevention was used or not, and how effective the foot disorder prevention method was. The return on prevention investment, as calculate by subtracting the herd-level total cost of lameness per cow-year with prevention from the herd-level total cost of lameness per cow-year without prevention, could be used to estimate the maximum amount a producer should be willing to pay for implementing a prevention strategy.

\section{Infectious Foot Disorder Prevention}

Figure 1 shows the return on prevention investment per cow-year when infectious foot disorder prevention was implemented, as affected by prevention effectiveness across the 3 digital dermatitis incidence rates. Regardless of incidence rate, the return on prevention investment increased as the effectiveness of prevention increased (i.e., the prevention RR became smaller) because fewer lameness cases were occurring and, therefore, expenditures and losses associated with lameness were lower. Additionally, as the incidence rate of digital dermatitis increased, the return on prevention investment increased because the potential to reduce lameness costs increased. In this example, we assumed that prevention focused on infectious foot disorders would reduce the incidence of digital dermatitis only, so the calculated returns on prevention investment were not affected by changes in the cost of other foot disorders included in the model (i.e., sole ulcer and white line disease).

Although the herd-level total cost of lameness per cow-year always decreased when infectious foot disorder prevention was implemented (Table 3), this is only beneficial to the herd if the decrease in costs is greater than or equal to the cost of prevention. The return on prevention investment per cow-year (mean \pm SD) when prevention effectiveness was low (prevention $\mathrm{RR}=0.91$ to 1.0) and the digital dermatitis incidence rate was originally 20,40 , or $60 \%$ was $\$ 0.6 \pm 0.4, \$ 1.2 \pm 0.9$, and $\$ 1.8 \pm 1.3$, respectively. In comparison, the return on prevention investment per cow-year when prevention effectiveness was high (prevention $\mathrm{RR}=0.00$ to 0.09 ) and the digital dermatitis incidence rate was originally 20,40 , or $60 \%$ was $\$ 12.2 \pm 3.0, \$ 24.4 \pm 6.0$, and $\$ 36.5$ \pm 9.0 , respectively. These values represent the estimated mean amount that could be spent on prevention in each scenario before there are negative economic 


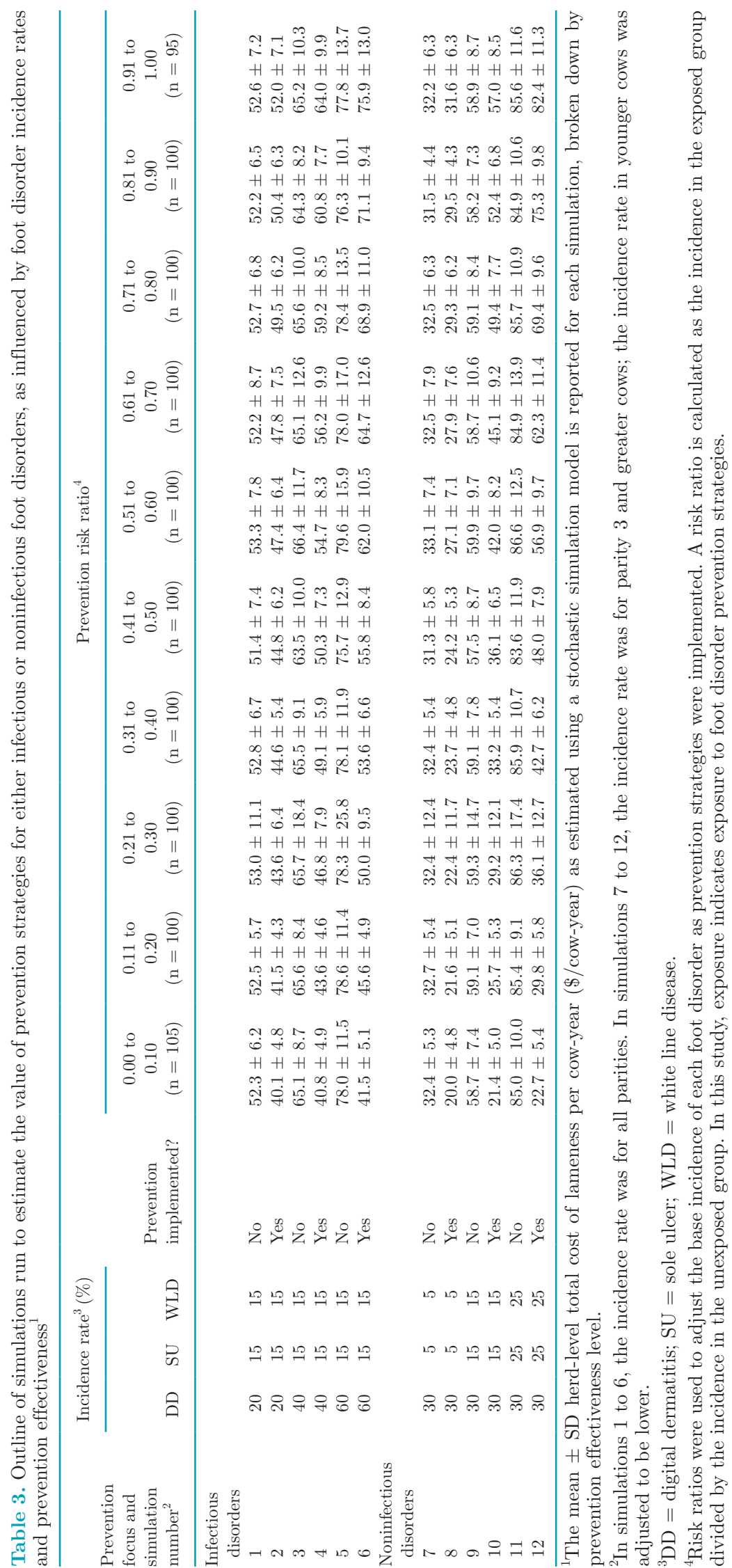


a)

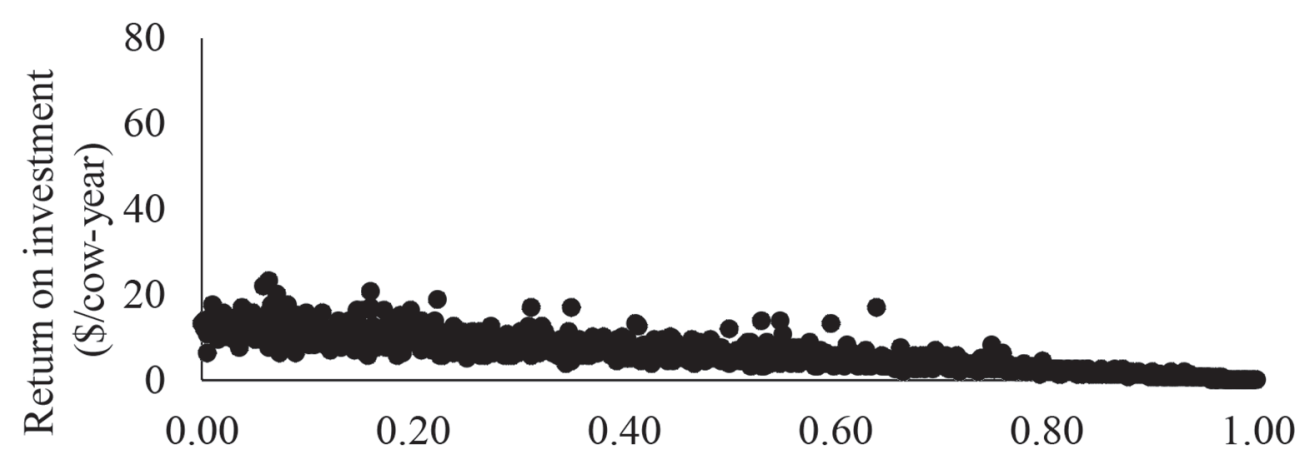

b)

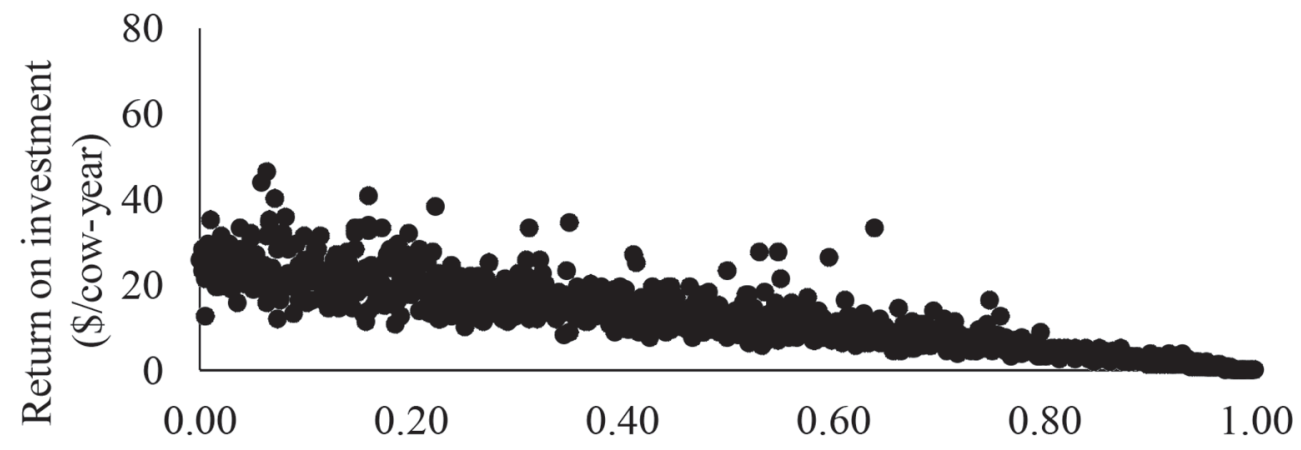

c)

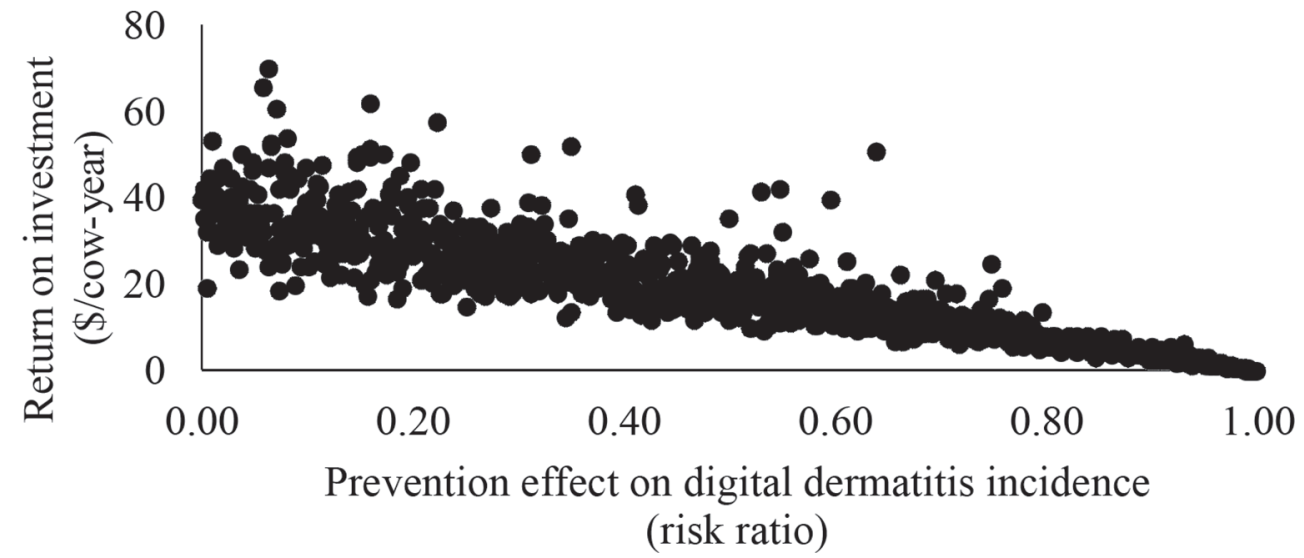

Figure 1. Return on foot disorder prevention investment per cow-year when infectious foot disorder prevention was implemented, as calculated using a stochastic simulation model ( $\mathrm{n}=1,000$ iterations). Three herd-level digital dermatitis incidence rates were tested: $20 \%$ (a), $40 \%$ (b), and $60 \%$ (c). The prevention effect on digital dermatitis incidence (risk ratio) was allowed to vary between 0.0 (highly effective) and 1.0 (ineffective).

consequences. The amount that could be spent on other combinations of incidence level and expected prevention effectiveness can be calculated from Table 3 .

The most common infectious foot disorder prevention strategy in the US dairy industry is footbaths. Multiple options exist for footbath solutions, with the 2 most common being $5 \%$ copper sulfate and formalin (Cook et al., 2012). If we assumed that a 5\% copper sulfate solution footbath costing $\$ 50$ per bath is utilized 1 time per day, 3 times per week, and changed after 200 cow passes, 0.78 baths would be needed per cow-year, for a total cost of prevention of $\$ 39 /$ cow-year. In our model, the mean return on prevention investment per cow-year was not enough to pay for using this prevention strategy, regardless of the incidence level of digital dermatitis or the level of prevention effectiveness (Table 3). There 
were some iterations where the return on prevention investment per cow-year was high enough to pay for implementing a copper sulfate footbath, but only when the prevention strategy was highly effective and the incidence rate of digital dermatitis was either 40 or $60 \%$. There were no scenarios when the incidence of digital dermatitis was $20 \%$ that the value of prevention was enough to offset the cost of this prevention strategy, regardless of prevention effectiveness (Figure 1). However, reduced footbath frequency or a less expensive supply of copper sulfate could change these results if no negative effects on footbath effectiveness were seen. Additionally, if the incidence rate of digital dermatitis was greater or if more benefits beyond digital dermatitis reduction are seen after footbath implementation (e.g., reduced foot rot), the footbath could still be profitable. Alternatively, if we assume a formalin footbath costing $\$ 12$ per bath and utilized at the same rate as assumed for the $5 \%$ copper sulfate bath, the total cost of prevention would be $\$ 9 /$ cow-year. In our model, the mean return on prevention investment per cow-year would cover the cost of this prevention method if the original incidence of digital dermatitis was $20 \%$ and at least a $70 \%$ reduction in disease was observed (prevention $\mathrm{RR} \leq 0.3$ ), if the original incidence of digital dermatitis was $40 \%$ and at least a $40 \%$ reduction in disease was observed (prevention $\mathrm{RR} \leq 0.6$ ), or if the original incidence of digital dermatitis was $60 \%$ and at least a $20 \%$ reduction in disease was observe (prevention $R R \leq 0.8$; Table 3). However, the potential human health concerns surrounding formalin use should be considered before adopting this prevention strategy.

\section{Noninfectious Foot Disorder Prevention}

Figure 2 shows the return on prevention investment per cow-year when noninfectious foot disorder prevention was implemented, as affected by prevention effectiveness across the 3 noninfectious foot disorder incidence rates. As in the infectious foot disorder prevention scenario, the return on prevention investment increased as the effectiveness of prevention increased (i.e., the prevention $\mathrm{RR}$ became smaller) and as the incidence rate of noninfectious disorders increased. Compared with when infectious foot disorder prevention was used, the value of prevention was generally greater, even though the original incidence rate of the selected disorders was lower. This resulted from noninfectious disorders costing more per case (Table 1) and the prevention strategy affecting the incidence of more than just a single disorder.

The return on prevention investment per cow-year (mean $\pm \mathrm{SD}$ ) when prevention effectiveness was low (prevention $\mathrm{RR}=0.91$ to 1.0 ) and noninfectious foot disorder incidence rates were originally 5,15 , or $25 \%$ in parity $\geq 3$ cows was $\$ 0.6 \pm 0.4, \$ 1.9 \pm 1.1$, and $\$ 3.2 \pm 1.9$, respectively. In comparison, the return on prevention investment per cow-year when prevention effectiveness was high (prevention $\mathrm{RR}=0.00$ to 0.09 ) and noninfectious foot disorder incidence rates were originally 5,15 , or $25 \%$ in parity $\geq 3$ cows was $\$ 12.4$ $\pm 1.5, \$ 37.3 \pm 4.6$, and $\$ 62.2 \pm 7.6$, respectively. The amount that could be spent on other combinations of incidence level and expected prevention effectiveness can be calculated from Table 3 .

Multiple noninfectious foot disorder prevention strategies exist; for example, preventive hoof trimming, biotin supplementation, and rubber flooring (Ettema and Østergaard, 2006). An estimated cost of preventive hoof trimming could be taken from the survey of hoof trimmers conducted by Dolecheck et al. (2018), where the cost for trimming per cow was $\$ 12.55 \pm 2.38$ (mean $\pm \mathrm{SD} ; \mathrm{n}=113$ survey respondents). Assuming the implementation of one additional trimming per cow-year, the mean value of this prevention strategy would be positive if the original incidence of noninfectious foot disorders was $15 \%$ and at least a $30 \%$ reduction in disease was achieved (prevention $\mathrm{RR} \leq 0.7$ ) or if the original incidence of noninfectious foot disorders was $25 \%$ and at least a $20 \%$ reduction in disease was achieved (prevention RR $\leq 0.8$; Table 3). Regardless of prevention effectiveness, the mean value of investing in this prevention strategy was never positive when the original incidence of noninfectious foot disorders was $5 \%$, although it was positive in some individual iterations where prevention was highly effective. The costs of some other noninfectious foot disorder prevention strategies are more difficult to calculate because they are typically not charged per cow. For example, reduction in lameness may be seen after installing rubber flooring (Vanegas et al., 2006) or redesigning poorly constructed freestalls (Ito et al., 2010), but the cost of doing so is a long-term investment that will have benefits beyond reducing the incidence of lameness (e.g., reduced mastitis incidence, improved cow longevity). Correctly identifying what portion of this cost should be considered expenditures on foot disorder prevention will affect whether the prevention investment is beneficial.

\section{Interpretation of Results}

Within this study, we focused on estimating the value of implementing either infectious or noninfectious foot disorder prevention. Based on the results in this study, the value of foot disorder prevention strategies depends 
a)

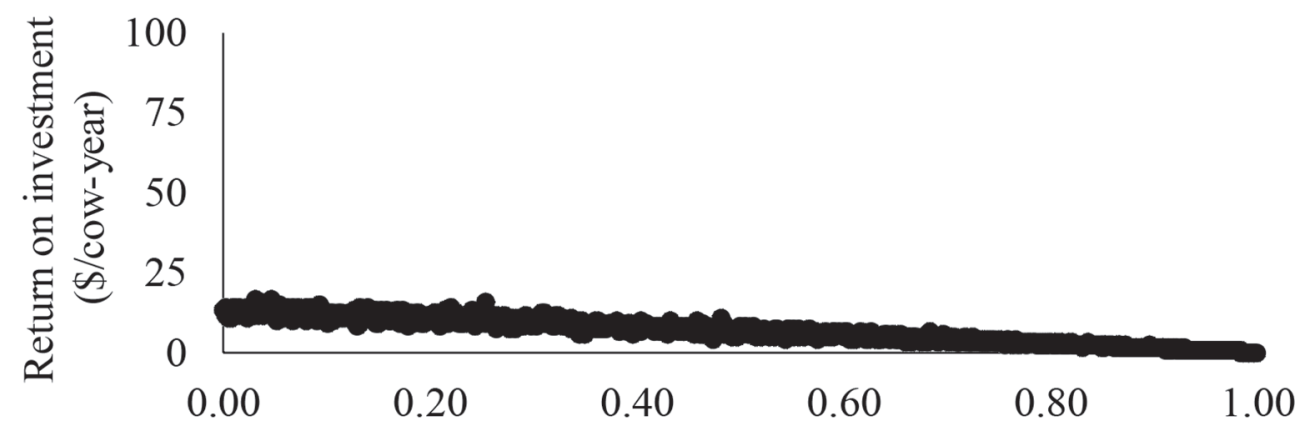

b)

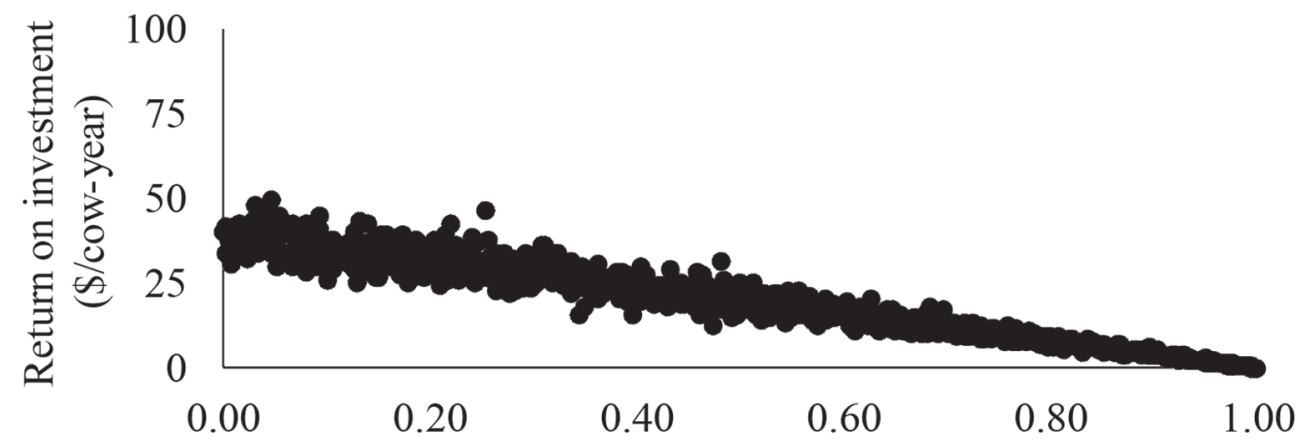

c)

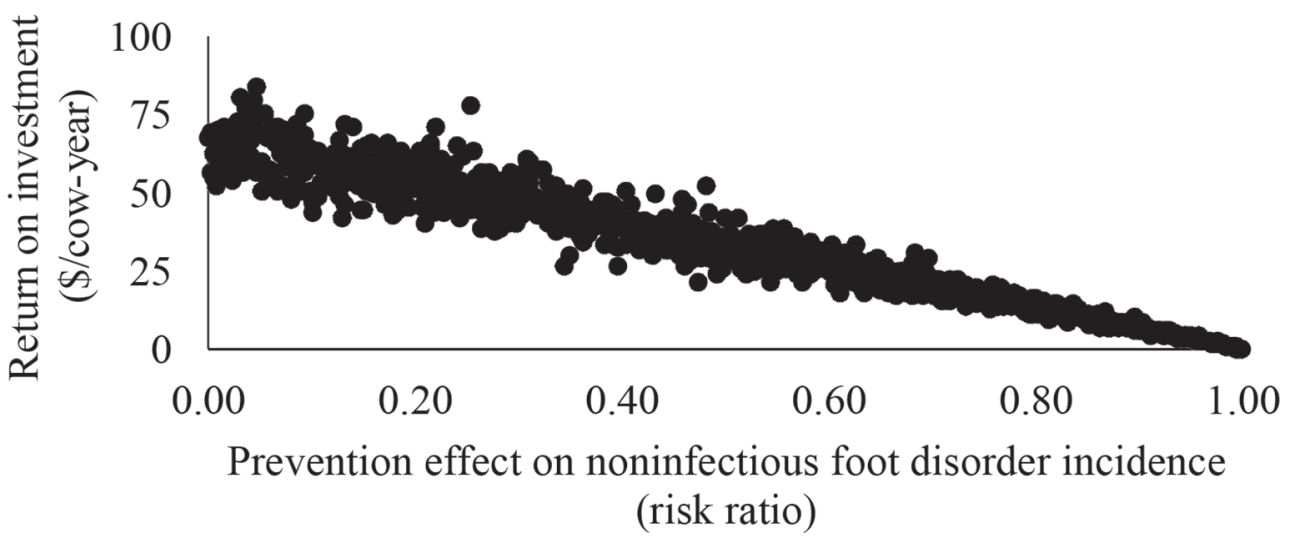

Figure 2. Return on foot disorder prevention investment per cow-year when noninfectious foot disorder prevention was implemented, as calculated using a stochastic simulation model $(\mathrm{n}=1,000$ iterations). Three noninfectious foot disorder (sole ulcer and white line disease) incidence rates were tested: $5 \%$ (a), $15 \%$ (b), and $25 \%$ (c) in parity 3 and greater cows; the incidence in younger cows was adjusted to be lower (see text for additional details). The prevention effect on noninfectious foot disorder incidence (risk ratio) was allowed to vary between 0.0 (highly effective) and 1.0 (ineffective).

on the incidence rate of foot disorders, the effectiveness of the prevention strategy implemented, and the cost of the prevention strategy implemented.

This model could be useful as a decision support tool to help guide decisions about investment in foot disorder prevention strategies. However, some limitations exist within the model. First, the model only accounted for 3 foot disorders, which were selected because they are the most prevalent lameness causing disorders in US dairy herds (DeFrain et al., 2013), and their effects on cow productivity have been studied more extensively than those of other foot disorders. However, by not including other foot disorders (e.g., foot rot, toe ulcers, thin soles), we may be underesti- 
mating the herd-level total cost of lameness and, therefore, the value of foot disorder prevention strategies. Additionally, the model assumed various relationships between foot disorders. For example, an assumption was made that changes in infectious foot disorder incidence would not influence noninfectious foot disorder incidence and vice versa. On the contrary, reducing one type of foot disorder will likely have a positive effect on other types of foot disorders. Again, this assumption may have contributed to reduced estimates of foot disorder prevention value.

Second, the model did not account for any benefits from adoption of foot disorder prevention beyond a reduction in foot disorders. Many foot disorder prevention strategies have the potential to reduce other problems. For example, changes in freestall design could simultaneously decrease lameness incidence, decrease mastitis incidence, and improve cow longevity. Additionally, there is a nonmonetary value of foot disorder prevention; for example, improved animal welfare. Decision-making regarding investment in foot disorder prevention should consider both economic and noneconomic factors.

Third, the model did not account for a herd improperly implementing prevention strategies. Poor implementation, including improper hoof trimming practices or footbath design, could lead to increased, rather than decreased, foot disorder incidence. Additionally, a positive response to prevention implementation will only be seen in herds with the correct stocking density and appropriate time budgets. If the prevention effectiveness were not limited to $\leq 1$ in this study, the estimated mean value of foot disorder prevention would be reduced. It is important to note that improper implementation of prevention strategies is not uncommon. For example, Cook et al. (2012) found, in a survey of 65 freestall dairy herds, that the number of cow passes between footbath solution changes ranged from 80 to 3,000, even though the industry recommendation is to change footbath solution after 100 to 300 cow passes. Given this, it is critical to consider the likelihood of proper implementation on a particular dairy during estimation of the value of foot disorder prevention.

Finally, the accuracy of model results is limited by the accuracy of the information provided to it. To accurately calculate the value of foot disorder prevention strategies, correct estimates are needed for the cost of foot disorders, the effectiveness of prevention, and foot disorder incidence rates within a herd. From researchers, further evaluation of the effects of specific foot disorders on cow performance and on the effect of prevention strategies on foot disorder incidence is needed to improve the accuracy of this decision support tool. Emphasis should be placed on the differences be- tween specific types of foot disorders. One assumption made in this study was that some effects of sole ulcers and white line disease were similar. Although both are noninfectious disorders, they do have different causes and epidemiology (Zinpro, 2014) and our assumption likely limits the accuracy of the model. At the farm level, managers must keep records on the incidence of specific foot disorders, not just lameness incidence, at the cow level to allow for the maximum benefit from a decision support tool like this one. By making these data available, improved decision-making surrounding the adoption of foot disorder prevention strategies could be accomplished.

Given the limitations of this model, it is important to acknowledge other efforts that have been made to estimate the value of foot disorder prevention. For example, Ettema and Østergaard (2006) used a dynamic, stochastic, and mechanistic Monte Carlo model known as SimHerd (Ostergaard et al., 2003) to evaluate the economic feasibility of strategies for preventing and controlling lameness. In that model, the risk of lameness incidence was modeled in a more detailed way by considering the effects of not only parity, but also the milk yield potential of individual cows, disease interrelationships, disease recurrence, and season (Ettema and Østergaard, 2006). Additionally, interdigital necrobacillosis and sole bruising were included in their analysis in addition to the 3 disorders included in the current study. In their evaluation of the value of footbaths, biotin supplementation, preventive trimming, rubber flooring, and decreased time on concrete, Ettema and Østergaard (2006) found that only implementation of footbaths and rubber flooring increased the return per cow-year (by $\$ 5.5$ and $\$ 22.4$, respectively, after accounting for inflation). Although the effects of specific prevention strategies were not calculated in the current study, a mean return similar to the estimate by Ettema and Østergaard (2006) for footbaths was estimated for implementing digital dermatitis prevention with a medium effectiveness of prevention.

The pros and cons associated with different modeling techniques and complexities should be kept in mind when choosing a model to support on-farm decision making. Although simplification may reduce a model's accuracy and reliability in some cases, the ability to quantify results in any way is an improvement over a producer's guess (Delorenzo and Thomas, 1996). Additionally, the relative expected consequences of an investment decision are often more important than exact numbers (Lien, 2003). For the current model, users should consider the outputs as estimates to aid in the first steps of decision making rather than exact expected outcomes from implementation of foot disorder prevention. 


\section{ACKNOWLEDGMENTS}

The authors thank Elanco Animal Health (Greenfield, IN), who provided funding to support this research.

\section{REFERENCES}

Adams, A. E., J. Lombard, C. Fossler, I. Román-Muñiz, and C. Kopral. 2017. Associations between housing and management practices and the prevalence of lameness, hock lesions, and thin cows on US dairy operations. J. Dairy Sci. 100:2119-2136.

Bewley, J., M. Boehlje, A. W. Gray, H. Hogeveen, S. Kenyon, S. Eicher, and M. Schutz. 2010. Stochastic simulation using @Risk for dairy business investment decisions. Agr. Financ. Rev. 70:97-125.

Booth, C. J., L. Warnick, Y. Gröhn, D. Maizon, C. Guard, and D. Janssen. 2004. Effect of lameness on culling in dairy cows. J. Dairy Sci. 87:4115-4122.

Cook, N. B., J. Rieman, A. Gomez, and K. Burgi. 2012. Observations on the design and use of footbaths for the control of infectious hoof disease in dairy cattle. Vet. J. 193:669-673.

DeFrain, J. M., M. Socha, and D. Tomlinson. 2013. Analysis of foot health records from 17 confinement dairies. J. Dairy Sci. 96:73297339.

Delorenzo, M., and C. Thomas. 1996. Dairy records and models for economic and financial planning. J. Dairy Sci. 79:337-345.

Dhuyvetter, K. C., T. L. Kastens, M. Overton, and J. Smith. 2007. Cow culling decisions: Costs or economic opportunity? Pages 173187 in Proc. Western Dairy Management Conf., Reno, NV. Oregon State University, Corvallis.

Dolecheck, K., and J. M. Bewley. 2018. Animal board invited review: Dairy cow lameness expenditures, losses, and total cost. Animal 12:1462-1474.

Dolecheck, K. A., R. M. Dwyer, M. W. Overton, and J. M. Bewley. 2018. A survey of United States dairy hoof care professionals on costs associated with treatment of hoof diseases. J. Dairy Sci. 101:8313-8326.

Dolecheck, K. A., M. W. Overton, T. B. Mark, and J. M. Bewley. 2019. Use of a stochastic simulation model to estimate the cost per case of digital dermatitis, sole ulcer, and white line disease by parity group and incidence timing. J. Dairy Sci. 102:715-730. https:/ /doi.org/10.3168/jds.2018-14901.

Ettema, J. F., and S. Østergaard. 2006. Economic decision making on prevention and control of clinical lameness in Danish dairy herds. Livest. Sci. 102:92-106.

FAPRI. 2018. U.S. Baseline Briefing Book: Projections for Agricultural and Biofuel Markets. Food and Agricultural Policy Research Institute (FAPRI) at the University of Missouri, https://www .fapri.missouri.edu/wp-content/uploads/2018/03/2018-Baseline -Outlook-1.pdf.

Gould, B. W., and M. Bozic. 2018. Understanding Dairy Markets. University of Wisconsin-Madison and University of Minnesota, http:/ /future.aae.wisc.edu/.

Groenendaal, H., D. Galligan, and H. Mulder. 2004. An economic spreadsheet model to determine optimal breeding and replacement decisions for dairy cattle. J. Dairy Sci. 87:2146-2157.

Hyde, J., and P. Engel. 2002. Investing in a robotic milking system: A Monte Carlo simulation analysis. J. Dairy Sci. 85:2207-2214.

Ito, K., M. Von Keyserlingk, S. LeBlanc, and D. Weary. 2010. Lying behavior as an indicator of lameness in dairy cows. J. Dairy Sci. 93:3553-3560.
Kertz, A. F., L. Reutzel, B. Barton, and R. Ely. 1997. Body weight, body condition score, and wither height of prepartum Holstein cows and birth weight and sex of calves by parity: A database and summary. J. Dairy Sci. 80:525-529.

Leach, K. A., H. R. Whay, C. M. Maggs, Z. E. Barker, E. S. Paul, A. K. Bell, and D. C. Main. 2010a. Working towards a reduction in cattle lameness: 1 . Understanding barriers to lameness control on dairy farms. Res. Vet. Sci. 89:311-317.

Leach, K. A., H. R. Whay, C. M. Maggs, Z. E. Barker, E. S. Paul, A. K. Bell, and D. C. Main. 2010b. Working towards a reduction in cattle lameness: 2 . Understanding dairy farmers' motivations. Res. Vet. Sci. 89:318-323.

Liang, D., L. M. Arnold, C. J. Stowe, R. J. Harmon, and J. M. Bewley. 2017. Estimating US dairy clinical disease costs with a stochastic simulation model. J. Dairy Sci. 100:1472-1486.

Lien, G. 2003. Assisting whole-farm decision-making through stochastic budgeting. Agric. Syst. 76:399-413.

Manske, T., J. Hultgren, and C. Bergsten. 2002. The effect of claw trimming on the hoof health of Swedish dairy cattle. Prev. Vet. Med. 54:113-129.

McInerney, J., K. Howe, and J. Schepers. 1992. A framework for the economic analysis of disease in farm livestock. Prev. Vet. Med. $13: 137-154$.

Morris, R. S. 1969. Assessing the economic value of veterinary services to primary industries. Aust. Vet. J. 45:295-300.

NAHMS. 2014. Dairy Cattle Management Practices in the United States. USDA-APHIS-VS, ed. National Animal Health Monitoring System, Fort Collins, CO.

Norman, H. D., J. R. Wright, M. T. Kuhn, S. M. Hubbard, and J. B. Cole. 2007. Genetic and environmental factors that affect gestation length. J. Dairy Sci. 90(Suppl. 1):264. (Abstr.)

NRC. 2001. Nutrient Requirements of Dairy Cattle. 7 th rev. ed. Natl. Acad. Press, Washington, DC.

Ostergaard, S., J. T. Sorensen, and C. Enevoldsen. 2003. SimHerd III: User's Manual. Internal Report No. 209. Danish Institute of Agricultural Sciences, Tjele, Denmark.

Silva del Río, N., S. Stewart, P. Rapnicki, Y. Chang, and P. Fricke. 2007. An observational analysis of twin births, calf sex ratio, and calf mortality in Holstein dairy cattle. J. Dairy Sci. 90:1255-1264.

Speijers, M. H. M., G. A. Finney, J. McBride, S. Watson, D. N. Logue, and N. E. O'Connell. 2012. Effectiveness of different footbathing frequencies using copper sulfate in the control of digital dermatitis in dairy cows. J. Dairy Sci. 95:2955-2964.

Vanegas, J., M. Overton, S. Berry, and W. Sischo. 2006. Effect of rubber flooring on claw health in lactating dairy cows housed in free-stall barns. J. Dairy Sci. 89:4251-4258.

VanRaden, P. M., and J. B. Cole. 2014. Lifetime Net Merit 2014. USDA. Accessed July 3, 2017. http://aipl.arsusda.gov/reference/ nmcalc-2014.htm.

von Keyserlingk, M., A. Barrientos, K. Ito, E. Galo, and D. Weary. 2012. Benchmarking cow comfort on North American freestall dairies: Lameness, leg injuries, lying time, facility design, and management for high-producing Holstein dairy cows. J. Dairy Sci. 95:7399-7408.

von Keyserlingk, M., J. Rushen, A. M. de Passillé, and D. M. Weary. 2009. Invited review: The welfare of dairy cattle - Key concepts and the role of science. J. Dairy Sci. 92:4101-4111.

Zinpro. 2014. Cattle lameness claw lesions: Identify, Prevent, Control. Zinpro Corporation, Eden Prairie, MN. 